Motrivivência Ano XXIII, No 36, P. 94-110 Jun./2011

doi: 10.5007/2175-8042.2011v23n36p94

\title{
A NECESSIDADE HISTÓRICA DA CULTURA CORPORAL: LIMITES E POSSIBILIDADES SOB A ORDEM CAPITALISTA
}

\author{
David Romão Teixeira' \\ Fernanda Braga Magalhães Dias²
}

\section{RESUMO}

Este artigo tem como objetivo apresentar uma reflexão sobre a constituição histórica da cultura corporal e o seu desenvolvimento na sociedade capitalista, apontando as particularidades da relação capital-trabalho-cultura corporal, a fim de identificar como o trato com o conhecimento da cultura corporal pode contribuir na formação dos trabalhadores no intuito de avançar qualitativamente na construção de possibilidades que atendam verdadeiramente às necessidades humanas, num processo lutas pela superação da ordem social vigente, rumo à emancipação humana.

Palavras-chave: Cultura corporal - Capital - Emancipação Humana

\section{Introdução}

Este artigo é resultado das reflexões realizadas no estudo de mestrado: "A necessidade histórica da cultura corporal em áreas de re- forma agrária: caso do MST/Bahia". Tem como objetivo apresentar uma reflexão sobre a constituição histórica da cultura corporal e o seu desenvolvimento na sociedade capitalista, apontando as particularidades da

1 Licenciado em Educação Física (UFBA). Mestre em Educação (UFSC). Professor Assistente do Centro de Formação de Professores da UFRB. Líder de grupo GEPEFE/UFRB e pesquisador do grupo LEPEL. Contato: david_romao@ufrb.edu.br

2 Licenciada em Educação Física (UEFS). Mestre em Educação (UFSC). Professora da rede estadual da Bahia. Contato: dias_fernanda@ymail.com 
relação capital-trabalho-cultura corporal, no sentido de avançar qualitativamente na construção de possibilidades de desenvolvimento da cultura corporal que atendam verdadeiramente às necessidades humanas, no processo de superação da ordem social vigente, rumo à emancipação humana.

No primeiro momento realizaremos uma breve apresentação da origem da necessidade histórica da cultura corporal. Em seguida discutiremos a forma hegemônica de manifestação da cultura corporal, e sua função principal no projeto ideológico do capital. A partir dessa análise, explicitaremos como a cultura corporal nos limites da sociabilidade do capital pode, ao mesmo tempo, contribuir para um projeto emancipador, participando da política cultural das organizações anticapitalistas.

\section{A necessidade histórica da cultura corporal}

Diante das diferentes definições presentes na produção teórica da Educação Física brasileira, fazemos a opção de deixar claro ao leitor o nosso entendimento do que é a cultura corporal, compreensão essa, desenvolvida sob a base do materialismo histórico, que a concebe como
[...] o fenômeno das práticas [corporais] cuja conexão geral ou primigênia - essência do objeto e o nexo interno das suas propriedades - determinante do seu conteúdo e estrutura de totalidade, é dada pela materialização em forma de atividades - sejam criativas ou imitativas das relações múltiplas de experiências ideológicas, políticas, filosóficas e outras, subordinadas à leis histórico-sociais. O geral dessas atividades é que são valorizadas em si mesmas; seu produto não material é inseparável do ato da produção e recebe do homem um valor de uso particular por atender aos seus sentidos lúdicos, estéticos, artísticos, agonísticos, competitivos e outros relacionados à sua realidade e às suas motivações. Elas se realizam com modelos socialmente elaborados que são portadores de significados ideais do mundo objetal, das suas propriedades, nexos e relações descobertos pela prática social conjunta (TAFFAREL; ESCOBAR, 2006, p.3).

Os elementos da cultura corporal, em conjunto com as atividades artísticas e lúdicas compõem o que Vieira Pinto (2005) chama de técnicas lúdicas:

[...] trata-se da resolução de uma contradição, apenas não 
de contradição direta, irrecusável e imposta, e sim de contradição que, tendo fundamento na constituição necessária do conjunto de atos vitais reclamados para a sobrevivência, adquiriu outra modalidade e se trava entre o homem e as finalidades, agora porém gratuitas, que impõe a si próprio ${ }^{3}$ (VIEIRA PINTO, 2005, p.210).

Essas atividades, ainda que não atendam a necessidades irrecusáveis e impostas pelo meio, são fundadas pelas mesmas. Enquanto elaborações livres se condicionam "a finalidades gratuitas surgidas pela vontade de imitação, não necessária, de atos efetivamente imperiosos como a caça, a contenda afinal, de que nascem os esportes e a luta contra os elementos" (VIEIRA PINTO, 2005, p.211). Nesse sentido, é que esses atos se originam de um ato vital coletivo imprescindível, constituindo-se como atividades indispensáveis enquanto uma imposição cultural - forma de vida mais elevada que ingressou o gênero humano, que com o passar do tempo, "torna-se interesse da atuação de alguns indivíduos, especializados por suas tendências, e termina, por força do uso cultural, por adquirir valor estético positivo, definitivamente fixado enquanto atividade criadora distinta" (VIEIRA PINTO, 2005, p.213).

As atividades corporais ao longo da história da humanidade vêm atendendo diversas necessidades humanas, desde as que se relacionam à existência imediata, como as que potencializam as capacidades do ser social. Na sua constituição com ser humano, os primatas tiveram que recorrer à sua corporalidade para garantir a sua existência, seja na sua defesa, na arte da caça, na construção dos abrigos, nos deslocamentos para fugir das intempéries da natureza. Nesse período a exigência de uma estrutura corporal forte e resistente era condição essencial, com o decorrer do seu desenvolvimento, com o processo de construção de ferramentas, armas mais sofisticadas, com o abandono gradativo do nomadismo, e com o início da domesticação dos animais, se diminui a centralidade da exigência física.

Com o aprimoramento das técnicas, não mais os grupos com maior vigor físico dominavam

3 Ainda que existam elementos da cultura corporal que atendem à necessidade de desenvolvimento da aptidão física do homem para exercitação, que julgamos ineliminável desse ser em estado social. O exemplo mais clássico de um desses elementos é a ginástica, uma forma sistematizada de exercitação corporal. Compreendemos que os elementos do condicionamento físico, a força, a flexibilidade, a agilidade e etc. foram e serão necessários ao homem em todas as formas sociais, seja para o trabalho ou para diversão. 
os territórios, mas sim os que possuíam também uma organização corporal orientada pelas novas criações humanas. Nem por isso a condição física deixou de ser uma preocupação constante da espécie, principalmente por causa dos confrontos entre os grupos humanos já organizados em núcleos. Nessa fase, principalmente guiados pelas lutas com outros povos, começou a ser ensinadas técnicas corporais de combate, ao contrário do período anterior, onde a atividade corporal se dava pura e simplesmente pela sua relação com a natureza, sem organização sistematizada, os objetivos ainda eram indicados pelo instinto de sobrevivência, assim como os outros animais.

Quanto mais elaboradas as criações humanas, expressão do desenvolvimento das forças produtivas, mais os homens atribuíam novos objetivos às práticas corporais, principalmente pela instituição de relações assimétricas de poder entre as camadas da sociedade, onde a produção dos meios de subsistência ficava destinada a uma parcela da população, alguns trabalhadores e escravos. A forma de organização social onde os homens exploram os próprios homens criou uma classe abastada que usufrui da riqueza produzida sem trabalhar - riqueza criada pelo trabalho alheio -, ficando livre para destinar seu tempo para as atividades de seu interesse. Diante dessa nova circunstância, a classe dominante criou atividades corporais que tem por objetivo atender ao belo, a estética e a guerra, não mais a subsistência imediata, sendo essas atividades cultuadas e repassadas sistematicamente às suas gerações com o objetivo do enobrecimento.

Com o "ócio digno" dessa classe, cria-se uma nova necessidade, a da nobreza através da beleza corporal atlética, e do prazer, que em conjunto com as atividades espirituais (a política, as artes, a filosofia) irá constituir o verdadeiro cidadão. Enquanto isso, a classe dos trabalhadores e escravos continuava a depender predominantemente do seu esforço físico para garantir a sua existência e a dos cidadãos (não-trabalhadores). Ainda nesse período, surgem as atividades atléticas responsáveis pela preparação militar, as corridas, os lançamentos de pesos, as primeiras lutas, assim como as competições que até nossos dias são apresentadas pelo lema Citius, Altius, Fortius.

Nesse breve retrospecto, chegamos ao feudalismo, onde o poder se concentrava nas mãos dos possuidores de terras (a Igreja, a Monarquia e a Aristocracia), que submetiam os trabalhadores à servidão para a produção de riqueza. Nesse período, por forte influência 
da igreja, as práticas corporais ganharam uma conotação depreciativa, principalmente as oriundas dos servos. Os festejos populares, principalmente relacionados com a colheita agrícola, eram marcados pelos jogos e danças comemorando os resultados da produção, ainda que a maior parte fosse destinada aos senhores. A presença dos circos nas feiras também era característica desta época, homens e mulheres que realizavam peripécias e acrobacias eram destaque entre as atividades apresentadas. Observamos aqui as práticas corporais atendendo novas necessidades humanas, o divertimento e o entretenimento, não dos que praticavam, mas sim dos que assistiam entre eles os reis, os senhores e os servos ${ }^{4}$.

Essas atividades, ensinadas de geração em geração, ocasionam a formação de companhias e grupos mambembes. Esses trabalhadores circenses, mesmo sendo artistas, ainda assim se encontram entre aqueles que dependem prioritariamente do seu esforço físico para garantir a sua existência. Agora não mais produzindo diretamente os seus meios de subsistência, mas sim o produto diversão.

Até então os elementos da cultura corporal não tinham sido sistematizados com o intuito de ampliar os níveis de produção, só a partir da ascensão da burguesia ao poder e da revolução industrial, esse conhecimento será cada vez mais sistematizado com o intuito de contribuir com o processo produtivo, no sentido de potencializá-lo, evitando esforços desnecessários e desenvolvendo métodos científicos de execução, no intuito de garantir a integridade física e a saúde para a produção ${ }^{5}$. Há aqui um esforço para que todas as esferas da vida atendam exclusivamente a explosão produtiva desta época.

Ainda que com o incremento das máquinas a vapor, a utilização do esforço físico humano continuava mais do que necessária, considerando as longas jornadas de trabalho dos operários, classe essa agora responsável pela produção da riqueza da sociedade, sob o controle da burguesia. Neste período surgem os métodos ginásticos, as primeiras modalidades esportivas,

4 "[...] no divertimento dos pobres, especialmente na $1^{\text {a }}$ metade do século XIX, vamos encontrar basicamente... "revistas de contos sentimentalóides, circos, pequenas exibições com uma atração principal, teatros mambembes e coisas semelhantes" (HOBSBAWM apud SOARES, 1997, p. 14).

5 Nesse sentido, surgiu ao longo do século XIX, a Ginástica científica, que baseando-se nos estudos científicos se apresentou "como contraponto aos usos do corpo como entretenimento, como simples espetáculo, pois, trazia como princípio a utilidade de gestos e a economia de energia", destacando que " a atividade física fora do mundo do trabalho, devia ser útil ao trabalho" (SOARES, 1997, p. 13). 
as danças sistematizadas, essas restritas à classe dominante, a qual ainda possuía tempo e condições físicas para a sua realização. Aos produtores de riqueza, os trabaIhadores, explorados ao máximo desde crianças, restam poucas possibilidades de prática corporal, inclusive com uma forte repressão as atividades que ofereciam risco à produção, por exemplo, as atividades circenses e acrobáticas, ou seja, continuam sem poder suprir as necessidades humanas até então já constituídas 6 .

Percebemos como no confronto com as adversidades da natureza e na sua relação com os outros homens, o ser social vai transformando o meio em que vive e ao mesmo tempo se auto-transformando, desenvolvendo técnicas e produzindo conhecimento de acordo com o avanço das forças produtivas e de suas velhas e novas necessidades produzidas historicamente. As práticas corporais foram adquirindo, com o passar dos anos, novas atribuições: garantia imediata da existência, preparação militar, satisfação do prazer, a estética, o divertimento, a saúde. Ainda que haja uma abundância, no modo de produção capitalista, essas necessidades não podem ser supridas pela grande maioria da população, muitos não podem usufruir das possibilidades plenas que os elementos da cultura corporal oferecem, condição própria das relações sociais vigentes.

Nesse sentido é que discutiremos como se desenvolve a cultura corporal sob a égide do capital, que tem como objetivo predominante a produção de maisvalia, e o elevado grau de desumanização, potencializando assim, a incapacidade de desenvolvimento pleno do ser social.

\section{A participação da cultura cor- poral na recomposição e disci- plinação da força de trabalho}

Para essa discussão é importante nos concentrar, na participação da cultura corporal no processo de recomposição da força de trabalho. Torna-se necessário dizer que "por força de trabalho ou capacidade de trabalho entendemos o conjunto das faculdades

6 Mesmo sob forte pressão da ideologia dominante da Revolução Industrial (ou seja, burguesa), representada pelo Metodismo e pelo Utilitarismo, no início desse período "[...] o ano de um trabalhador ainda se compunha de ciclos de grande fadiga e provisões escassas, intercaladas por dias de festa, em que a bebida e a carne eram mais abundantes, as crianças ganhavam laranjas e fitas, e as danças, o namoro, as visitas sociais e os esportes envolviam o povo" (THOMPSON, 1987, p.287, grifo nosso). 
físicas e espirituais que existem na corporalidade, na personalidade viva de um homem e que ele põe em movimento toda vez que produz valores de uso de qualquer espécie" (MARX, 1988, p. 135).

A força de trabalho é a mercadoria central na "imensa coleção de mercadorias" da sociedade capitalista, indispensável à produção e reprodução do capital. Para que sua utilização satisfaça plenamente ao seu comprador, devem ser garantidas as condições mínimas necessárias para a sua produção e a reprodução, e sendo a força de trabalho a única propriedade - e indissociável - do trabalhador, o mesmo precisa estar em boas condições para poder vendê-la ao capitalista, pois essa é a sua única forma de manter-se vivo nesta forma social.

O capitalista (comprador da força de trabalho) cria todas as condições necessárias para consumir ao máximo as mercadorias por ele compradas. Nesse sentido, irá consumir o quanto for possível da força de trabalho também, no primeiro momento ampliando sua jornada de trabalho (mais-valia absoluta) e, em seguida, incrementando com o desenvolvimento das forças produtivas, novas técnicas, máquinas e novas formas de organização e gestão da produção (maisvalia relativa) todos imbuídos numa só tarefa, a produção de mais-valia (MARX, 1988).

Diante da centralidade da força de trabalho para a produção capitalista, a sua recomposição é de extrema importância tanto para o capital como para os trabalhadores. Marx ressalta que, "[...] se não é vendida, de nada serve ao trabaIhador, ele então a percebe muito mais como uma cruel necessidade natural que a sua capacidade de trabalho tenha exigido determinado quantum de meios de subsistência para sua produção e constantemente exige de novo para a sua reprodução" (MARX, 1988, p.139). Diante dessa circunstância o possuidor da força de trabalho é forçado a vendêla ao capitalista para garantir a sua existência.

A recomposição orgânica do possuidor da força de trabalho é estritamente de caráter fisiológico, pois, apesar de apresentarem diferenças qualitativas, as atividades produtivas são antes de tudo "dispêndio produtivo de cérebro, músculos, nervos, mãos etc. humanos", e precisam de um conjunto de condições para se efetivar. Por isso sob os ditames estritos da sociedade capitalista, os elementos da cultura corporal atendem prioritariamente aos anseios de recompor e disciplinar a força de trabalho, restringindo a capacidade de desenvolvimento do ser social na tentativa de transformá-lo em cordial 
produtor de mais-valia. Harvey chama atenção para a disciplinacão dos trabalhadores na sociedade capitalista:

A disciplinação da força de trabalho para os propósitos de acumulação do capital [...] é uma questão muito complicada. Ela envolve, em primeiro lugar, alguma mistura de repressão, familiarização, cooptação e cooperação, elementos que têm de ser organizados não somente no local de trabalho como na sociedade como um todo. A socialização do trabalhador nas condições de produção capitalista envolve o controle social bem amplo das capacidades físicas e mentais. (HARVEY, 2005, p.119, grifo nosso)

Esse processo de disciplinação é de tal importância para o capital que, mesmo com a ação do Estado ao seu favor, os capitalistas não querem perder o controle desse processo. Como garantia de sua intervenção eles atuam diretamente na elaboração e implementação de projetos, através de seus agentes de mediação, no caso brasileiro: Banco Mundial e o FMI; e de organizações civis como: o "Sistema $\mathrm{S}^{\text {"7 }}$ e as organizações não-governamentais (FERRETI, 2005). As relações, semeIhanças e objetivos, do Lazer, Esporte e da Educação Física escolar com o trabalho na forma capitalista é de fácil identificação, apesar de existir duras críticas muitos pesquisadores da área ainda defendem a neutralidade política das práticas corporais, conforme indica Taffarel,

Olhar o Desporto isolado, fora do contexto de inter-relações é atribuir-lhe uma autonomia inexistente. As visões idealistas de que o desporto é algo bom em si mesmo e que paira acima dos conflitos e confrontos humanos e sociais, já foram severamente criticadas por estudiosos como Nobert Elias, Bourdieu, Bracht, Assis de Oliveira, entre outros (TAFFAREL, 2001, p.603).

A partir do séc. $X X$, as semelhanças do esporte com a organização do trabalho, é mais perceptível, confirmando a tese das semelhanças do trabalho industrial e o esporte de rendimento, ambos tendo características comuns como: disciplina, autoridade, concorrência, rendimento, racionalidade téc-

7 O "Sistema S" é composto por instituições de formação profissional ligadas ao empresariado, mantidas por contribuição parafiscal. São elas SENAI (Serviço Nacional de Aprendizagem Industrial), SENAC (Serviço Nacional de Aprendizagem Comercial), SENAT (Serviço Nacional de Aprendizagem do Transporte), e SENAR (Serviço Nacional de Aprendizagem Rural) (FERRETI, 2005). 
nica, organização e burocratização (RIGAUER, 1969 apud BRACHT, 2005). Além das semelhanças com o taylorismo/fordismo, percebe-se na produção teórica do Toyotismo as particularidades dos termos e objetivos utilizados também no esporte.

[...] o Sistema Toyota faz apelo "à habilidade e ao talento dos jogadores individuais" que devem agir como uma "equipe envolvida em atingir um objetivo preestabelecido". Para isto, "é necessário um sistema de gestão total que desenvolva a habilidade humana até sua mais plena capacidade, a fim de melhor realçar a criatividade e a operosidade" das individualidades envolvidas na produção (OHONO, 1997, p.30). E ainda: "o treinador", eufemismo utilizado para designar o chefe de um determinado grupo de trabalhadores, deve "pegar as mãos dos operários e ensinálos. Isso gera confiança no supervisor. Ao mesmo tempo, os operários devem ser ensinados a ajudar uns aos outros" (OHONO, 1997, p.27 apud SANTOS, 2006, p.225-226).

Essa relação direta do esporte com o trabalho industrial, e a propagação da neutralidade em relação aos problemas sociais, serviram para tornar o esporte de rendimento num fenômeno social de grande proporção e aceitação em todo mundo. A indústria esportiva vem apresentando grandes índices de desenvolvimento nos últimos anos, e seus princípios tornaram-se hegemônicos em relação às outras práticas corporais, seja no sistema formal ou informal de educação.

No que trata das práticas corporais fora do sistema formal de ensino, ela é também atrelada diretamente ao trabalho, pois os conteúdos e o tempo disponível para essas atividades são controlados através do sistema de interiorização do capital. Esse tempo liberado que no modo capitalista de produção nada tem de livre, serve prioritariamente para a recomposição da força de trabalho e sua dominação pelo capital.

Nesse contexto é que surge o Lazer, como momento de "liberdade" do trabalhador para atividades fora do tempo de trabalho. As atividades de lazer geralmente são organizadas no intuito de contribuir com o processo de alienação dos trabalhadores, assim como, impossibilitam a organização dos mesmos enquanto classe. Nos dias de hoje, a indústria do Lazer - que também se destacou nos últimos anos - se encarrega de organizar o que o trabalhador deve fazer nesse tempo liberado. 
$\mathrm{Na}$ esfera escolar as práticas corporais não se diferenciam muito das atividades fora dela, o esporte de rendimento com seus objetivos já citados aqui, predomina no sistema educacional, preparando a futura força de trabalho para o momento posterior, e para o consumo dos materiais da indústria esportiva. Percebe-se que a Educação Física, disciplina escolar responsável pelo trato com os conhecimentos da cultura corporal, desde sua participação na escola em meado do século XIX, ainda que impregnada pela concepção médico-higienista, já apresentava o objetivo de combater as mazelas da vida urbana e de formar a força de trabalho cada vez mais produtiva, de acordo com as necessidades da política econômica e ideológica da burguesia brasileira.

As práticas corporais fora do espaço de trabalho se destacam atualmente na realidade social dos trabalhadores na forma de uma qualidade de vida a ser comprada - em geral, com a indústria do fitness, e dentro da esfera do trabalho, por meio da Ginástica Laboral, alternativa paliativa para os problemas das árduas horas de trabalho e o alto grau de exploração dos trabalhadores.

Para demonstrar o equívoco e a intenção dos que defendem que as atividades corporais são desprovidas de qualquer intencionalidade política, apresentaremos mais um elemento para essa discussão, a ação dos capitalistas no controle e organização das práticas corporais dos trabalhadores, que no Brasil é representada pelo "Sistema S", organização civil do empresariado brasileiro $^{8}$. Essa organização se destaca entre outras atividades realizadas, pelo grande investimento no que se refere às práticas corporais e de lazer dos trabalhadores, intervindo na capacitação de profissionais, assessoria

8 Requixa (1977) confirma tal análise de forma insuspeita, já que ele propala as atividades deste sistema defendendo sua positividade, longe de qualquer pretensão revolucionária, conforme podemos asseverar em seu escrito:

Problemas decorrentes da falta de aparelhamento das cidades para atender os novos contingentes humanos, imediatamente se fizeram sentir em todos os setores: transporte, habitação, assistência, recreação e outros serviços. Ademais, os hábitos, costumes e formas de vida, que se exprimem através de maneiras de pensar, sentir, agir, diferindo no homem do campo e no homem da cidade, permitiam o surgimento de conflitos entre as novas exigências e os padrões tradicionais de comportamento.

Sensíveis à situação que se delineava, as classes empresariais propõem ao Governo Federal o custeio de instituições que trouxessem ativa contribuição para o equacionamento e solução dos problemas emergentes. O Governo federal aceita a proposição e, em 1946, autoriza a Confederação Nacional da Indústria e a Confederação Nacional do Comércio a criarem, respectivamente, o SESI e o SESC, a serem mantidos, exclusivamente, através de contribuição compulsória do empresariado industrial e comercial brasileiro (REQUIXA, 1977, p.32). 
de projetos, realização de eventos ${ }^{9}$, congressos, construção de clubes, dentre outros. Configurando o esforço dos capitalistas em controlar a vida dos trabalhadores.

Outra opção oferecida pelo atual projeto societal é a utilização da educação, das artes e dos elementos da cultura corporal como a salvação das mazelas produzidas, e/ou para recuperação das vítimas desta forma social. Isso pode ser observado pelas iniciativas do terceiro setor, capitaneados pelas organizações não-governamentais que se proliferaram realizando atividades "sócio-educativas", "artísticoeducativas" e esportivas, com o objetivo de oferecer para as pessoas em "risco social" uma formação para a empregabilidade e para a sustentabilidade no capital.

Essas organizações da sociedade burguesa promovem por meio de atividades elaboradas com os elementos da cultura corporal uma formação que ilude principalmente as crianças e jovens pobres do nosso país, inculcando-lhes que é possível "vencer na vida", "ser um bom cidadão", através destas atividades. Enquanto os filhos da burguesia podem acessar uma formação que dispõem do que há de mais avançado no campo intelectual, tecnológico e da cultura corporal. Proporcionando uma grande ilusão, uma anestesia social, uma formação que atende aos objetivos da burguesia para com os trabalhadores, com o intuito de mantê-los sob seu controle e garantindo a perpetuação da sua dominação de classe.

Nessa breve discussão, percebe-se a relação permanente, mediada, e necessária entre os elementos da cultura corporal e o trabalho. No intuito de perpetuar a sua dominação, os capitalistas não abrem mão do controle sobre os trabalhadores, tentando impedir a todo custo à organização e o desenvolvimento da consciência de classe dos trabalhadores, e nesse esforço utiliza-se também das práticas corporais.

A cultura corporal, assim como as artes, transcendem as atividades vitais que lhes dão origem, realizando uma passagem do funcional ao lúdico. Na sociedade do capital podemos observar uma transformação do lúdico para atender os anseios da produção de mais-valia, incorporando uma funcionalidade também ao lúdico, prendendo-o ao utilitarismo comum nas relações sociais do capital. No contexto atual do capital, as práticas corporais perdem sua ênfase na formação básica dos

9 Como exemplo o ENAREL (Encontro Nacional de Recreação e Lazer) evento apoiado pelo "Sistema S". 
trabalhadores e, ao mesmo tempo ganham destaque enquanto mercadoria de luxo (NOZAKI, 2004). E quando atreladas ao trabalho na sua forma capitalista, estão sempre ligadas ao processo de alienação e recomposição da força de trabalho. Segundo Mészáros,

Seria ilusório esperar modificações significativas, nesse aspecto. A única forma de contabilidade conhecida do capitalismo é uma estreita contabilidade monetária, e o exame sério dos problemas do "tempo livre" (não do "lazer" ocioso) exige uma abordagem radicalmente diferente: a instituição de uma contabilidade social, numa sociedade que tenha conseguido emancipar-se das pressões mutiladoras das mediações de segunda ordem da produção de mercadoria. Como vimos, a ideologia burguesa, já desde Adam Smith, só podia examinar o problema da educação e do lazer em termos limitadamente utilitários: como "diversão da mente", destinada em parte a restabelecer as energias do trabalhador para a monótona rotina do dia seguinte, e em parte mantê-los longe dos desperdícios da "libertinagem" (MÉSZÁROS, 2006, p. 278).

A perspectiva hegemônica das práticas corporais alinha-se ao sistema de interiorização do capital, indo contra os interesses da classe trabalhadora, favorecendo o processo de alienação, no intuito de transformá-los em meros produtores descartáveis de mais-valia. Por isso, nos preocupamos em identificar como o trato com o conhecimento da cultura corporal pode contribuir com os trabalhadores nesse desafio de superação do capital.

\section{A cultura corporal para além do capital}

Procuramos entender como o trato com a cultura corporal pode possibilitar a superação do modo de produção capitalista, qual a sua participação na manutenção do status quo vigente, e como esta pode servir à classe trabalhadora na sua luta contra o capital. Reconhecemos que as práticas corporais precisam contribuir com o processo de emancipação humana, sendo de fundamental importância combater as teorias que irão dissociar a educação e a cultura corporal das relações de produção, pois essas, ao contrário do que dizem, possuem um posicionamento político definido que visa manter a classe trabalhadora sob os ditames do capital.

Diante das contradições próprias da forma como o capital se organiza é que encontramos os motivos para sua derrocada, 
concordando com a análise de Coggiola, segundo a qual: "Se é correto apontar que a lógica capitalista cria as bases da barbárie, é unilateral fazê-lo sem dizer que cria ao mesmo tempo as bases do contrário da barbárie: a revolução socialista mundial" (2001, p.40). Por isso, compreender como os trabalhadores podem organizar o seu "espaço fora do trabalho" para além dos objetivos da recomposição da força de trabalho é imprescindível, por mais que consideremos importante o desenvolvimento da aptidão física dos trabalhadores para a luta, isso, porém, é insuficiente dentro das possibilidades que a cultura corporal oferece.

Esse processo de formação revolucionária precisará ocorrer sob a orientação dos organismos de classe dos trabalhadores, como: partidos, sindicatos, movimentos sociais, etc., com a formação de militantes culturais e de círculos populares de esporte e lazer, que poderão oferecer subsídios essenciais para formação cultural dos trabalhadores. No ordem do capital, o limite dessas iniciativas se apresentam só como preparativos para revolução, já que somente sob outra base social será possível uma formação omnilateral ${ }^{10}$. Por isso caminhamos com aqueles que acreditam na possibilidade de uma outra ordem social, onde os homens possam executar sua auto-construção autêntica, ou seja, sem a mediação fundante do capital. Trotski nos apresenta com muita propriedade esse vir-a-ser emancipador da seguinte forma:

No desenvolvimento da nova sociedade de certo chegará um momento em que a economia, a edificação cultural e a arte terão maior liberdade de movimento para avançar. Quanto ao ritmo desse desenvolvimento, agora só podemos imaginar. A sociedade futura irá se descartar da áspera e embrutecedora preocupação do pão de cada dia. Os restaurantes coletivos prepararão à escolha de cada um, comida boa, sadia e apetitosa. As lavanderias públicas lavarão bem as roupas. Todas as crianças serão fortes, alegres, bem alimentadas e absorverão os elementos fundamentais da ciência e da arte, como a albumina, o ar e o calor do sol. A eletricidade e o rádio não usarão mais os métodos primitivos de

10 Utilizamos a referência de Manacorda, onde desenvolvimento da formação humana omnilateral deve ser entendida como "o chegar histórico do homem a uma totalidade de capacidades e, ao mesmo tempo, a uma totalidade de capacidades de consumo e gozo, em que se deve considerar sobretudo o usufruir dos bens espirituais (plano cultural e intelectual), além dos materiais." (1991, p. 81). 
hoje, mas sairão de fontes inesgotáveis de energia concentrada ao aperto de um botão. Não haverá bocas inúteis. O egoísmo libertado do homem - imensa força!- irá se voltar de todo para o conhecimento, a transformação e o melhoramento do Universo (TROTSKI, 2007, p.152).

A classe trabalhadora já demonstrou historicamente a sua capacidade de organização das práticas corporais de acordo com seus interesses em determinados períodos da luta de classes ${ }^{11}$, é preciso por dentro dos seus organismos repensar a importância de outra possibilidade no trato com o conhecimento da cultura corporal, que não pode ser qualquer prática, muito menos a predominante na sociedade capitalista. Trata-se de apresentar outros princípios (como a solidariedade de classe, o desenvolvimento criativo das práticas corporais, a ampliação do repertório cultura corporal, o autoconhecimento corporal e etc.), que auxiliem no processo de emancipação humana e na transformação radical da sociedade.

A educação física para além do capital deve se desenvolver em todos os espaços possíveis de formação dos trabalhadores, mesmo diante de todas as adversidades existentes, pois, "a Educação Física pode dar seus passos mediadores em direção ao futuro começando pelo imediato, iluminado pelo espaço que ela pode, legitimamente, ocupar dentro da estratégia global orientada pelo futuro que se vislumbra" (TAFFAREL; ESCOBAR, 200[8]-a, p.12).

Dessa forma, estimular, criar condições e desenvolver o aprendizado das técnicas lúdicas, é oferecer ao gênero humano a forma de vida mais elevada na qual ingressou essa espécie, ainda que de forma limitada sob a forma capitalista. É necessário a sistematização e organização das atividades corporais, pois os indivíduos envolvidos nessas atividades irão exigir cada vez mais novos avanços compatíveis com suas novas conquistas e necessidades. Ao mesmo tempo em que seus objetivos são atingidos, ela participa na transformação do ser social, tornando-o mais humano, estimulando suas potencialidades.

O atual contexto leva Mészáros a afirmar que:

11 “A classe trabalhadora em países como a Bélgica, a Tchecoeslováquia, a França e principalmente a Alemanha criou uma organização de clubes de ginástica e, posteriormente, também de esporte, própria que procurava diferenciar-se das organizações ginásticas e esportivas "burguesas". Este movimento produziu textos (de jornais e mesmo livros) onde os princípios que norteavam suas atividades bem como as críticas ao esporte "burguês" estavam expressas" (BRACHT, 2005, p. 24). 
[...] a tarefa de "emancipar todos os sentidos e atributos humanos" está longe de ser resolvida por uma compreensão correta das complexas interrelações dos poderes humanos. O problema, como Marx o vê, consiste no fato de que o homem, devido à alienação, não se apropria de "sua essência omnilateral como um homem total", mas limita sua atenção à esfera da mera utilidade. Isso acarreta um extremo empobrecimento dos sentidos humanos (MÉSZÁROS, 2006, p.183).

Posicionamo-nos de maneira contrária àqueles que apontam como alternativa, nesse desafio, a concentração dos esforços da classe trabalhadora apenas na educação como possibilidade de sua emancipação. Também estamos em discordância com aqueles que defendem a absolutização total das coisas, sob o argumento de que é degenerado tudo o que é produzido no seio de uma sociedade degenerada. Alinhamo-nos com os que conseguem compreender a importância da elevação do nível do padrão cultural da classe trabaIhadora, sem dissociá-la da tarefa principal que se apresenta da luta de classes, o confronto direto com os capitalistas.

Nesse sentido, enveredamos pela possibilidade da classe trabalhadora usufruir de todo patrimônio histórico da humanidade, de todos os avanços, inclusive os empreendidos pela sociedade burguesa, para utilizá-los no processo revolucionário ${ }^{12}$ e na construção do socialismo. Reconhecemos a importância da formação da classe trabalhadora sobre outros pilares, tendo a revolução como a ordem do dia. Os trabalhadores historicamente já demonstraram que é possível e necessário um outro projeto de formação, uma outra forma de utilização do "espaço fora do trabalho". Nesse sentido, a cultura corporal contribuirá na formação dos trabaIhadores para além da necessidade única da recomposição da força de trabalho, da sua utilização no processo de alienação ${ }^{13}$.

12 Entendemos a revolução de acordo com a definição de Trotski: "A Revolução é a luta da classe operária para conquistar o poder, estabelecer seu domínio, reconstituir a sociedade. Ela passa pelos pontos mais elevados, os mais agudos paroxismos de uma luta sangrenta. Permanece, no entanto, una e indivisível em todo o seu curso, desde o tímido início até o término ideal, quando o Estado organizado pela Revolução se dissolverá na sociedade comunista" (TROTSKI, 2007, p.89-90).

13 O que pode significar o afastamento da vida voltada ao trabalho, do início ao fim, enquanto meio para produção e reprodução do capital. "A concepção do "tempo livre" como veículo que transcende a oposição entre o trabalho mental e o físico, entre a teoria e a prática, entre criatividade e rotina mecânica, e entre fins e meios, sempre ficou muito longe do horizonte burguês" (MÉSZÁROS, 2006, p. 278). 
Apontamos como tarefa imprescindível, que os trabalhadores assumam os rumos do seu processo de formação, e a possibilidade disso só poderá acontecer de forma plena em outro modo de produzir e reproduzir a existência, onde os trabalhadores possam produzir de forma livre e associada. Desta forma, a classe trabalhadora precisa avançar na luta pela destruição da forma capital de produzir a vida, e nesse empreendimento utilizar como recurso os elementos da cultura corporal.

\section{Referências}

BRACHT, Valter. Sociologia Crítica do Esporte: uma introdução.

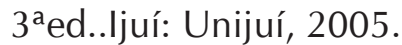

C OGG I O L A, Osva Id o . "Globalização", economia e cultura. In: Universidade e ciência na crise global. São Paulo: Xamã, 2001.

FERRETTI, Celso João. Empresários, trabalhadores e educadores: Diferentes olhares sobre as relações trabalho e educação no Brasil nos anos recentes. In: LOMBARDI, J.C. et al (Orgs.). Capitalismo, trabalho e educação. Campinas: Autores Associados, p. 97-118, 2002.

HARVEY, David. Condição pósmoderna. $2^{\text {a }}$ ed. São Paulo: Loyola, 1993.
MANACORDA, M. A.. Marx e a pedagogia moderna. Editora Alínea: Campinas/SP, 2007.

MARX, Karl. O Capital: Crítica da Economia Política. Vol. I, Tomo.I, Cap. I, $3^{\text {a }}$ ed. São Paulo: Nova Cultural, 1988.

MÉSZÁROS, István. A teoria da alienação em Marx. São Paulo: Boitempo, 2006.

NOZAKI, H, T. O mundo do trabalho e transformações na educação física brasileira. 2004. Tese (Doutorado em Educação) - Universidade Federal Fluminense, Niterói, 2004. REQUIXA, Renato. O lazer no Brasil. São Paulo: Brasiliense, 1977.

SANTOS, Ariosvaldo. Antigo e novos campos da ideologia do capital na educação do trabalhador. In: ALVES, Giovanni (org). Trabalho e Educação: contradições do capitalismo global. Maringá: Editora Práxis, 2006.

SOARES, C. L.. Imagens do Corpo educado: um olhar sobre a ginástica no século XIX. In: Amarílio Ferreira Neto. (Org.). Pesquisa Histórica na educação Física. $1^{\text {a }}$ ed. Vitória: UFES, v. 2, p. 05-32, 1997.

TAFFAREL, Celi N. Z.. Desporto Educacional: realidade e possibilidades das políticas governamentais e das práticas pedagógicas nas escolas públicas. 
In: CONFERÊNCIA NACIONAL DE EDUCAÇÃO, CULTURA E DESPORTO. Desafios para o século XXI: coletânea de textos da I Conferência Nacional deEducação, Cultura E Desporto. Brasília: Câmara dos Deputados, Coordenação de Publicações, 2001.

TAFFAREL, Celi Zulke; ESCOBAR, Micheli Ortega. Mas, afinal, o que é educação física? Reafirmando o marxismo contra o simplismo intelectual. [2008?]-a. Disponível em: http://www.faced.ufba.br/ rascunho_digital/. Acessado em: 10 de outubro de 2008.

TAFFAREL, Celi Zulke; ESCOBAR, Micheli Ortega. A cultura corporal e os dualismos necessários para a ordem do capital. [2006?]. Disponível em: http://www.faced.ufba.br/ rascunho_digital/. Acessado em: 10 de março de 2006.

THOMPSON, E. P. A formação da classe operária inglesa. Vol. III. São Paulo: Paz e Terra, 1987, p.287.

TROTSKY, Leon. Literatura e

Revolução. Rio de Janeiro: Jorge Zahar Ed., 2007- a.

VIEIRA PINTO, Álvaro. O conceito

de tecnologia. Rio de Janeiro:

Contraponto, 2005.

\section{ABSTRACT}

This article aims to present a reflection on the historical constitution of body culture and its development in capitalist society, pointing out the peculiarities of the capital-laborculture body in order to identify how the deal with the knowledge of body culture can contribute to training workers for the purpose of moving forward in building opportunities that meet real human needs, a process of overcoming struggles for social order, towards human emancipation.

Keywords: Body Culture - Capital - Human Emancipation

Recebido: março/2011 Aprovado: julho/2011. 